\title{
Treatment of Early Parkinson's Disease
}

\section{Part 2}

\author{
Tanya Simuni $^{a}$ Kelly E. Lyons ${ }^{c}$ Rajesh Pahwa ${ }^{c}$ Robert A. Hauser ${ }^{d}$ \\ Cynthia Comella $^{b}$ Lawrence Elmer ${ }^{e}$ Daniel Weintraub ${ }^{f}$
}

a Parkinson's Disease and Movement Disorders Center and Department of Neurology, Northwestern University, and ' ${ }^{\text {Department }}$ of Neurological Sciences, Rush University Medical Center, Chicago, III., 'Parkinson Disease and Movement Disorder Center and Department of Neurology, University of Kansas Medical Center, Kansas City, Kans., 'Parkinson's Disease and Movement Disorders Center and Departments of Neurology, Pharmacology and Experimental Therapeutics, University of South Florida, Tampa, Fla., ${ }^{e}$ Center for Neurological Disorders and Department of Neurology, University of Toledo, Toledo, Ohio, and f Departments of Psychiatry and Neurology, University of Pennsylvania, Philadelphia, Pa., USA

\section{Key Words}

Parkinson's disease - Dopamine agonists - Monoamine

oxidase B inhibitors · Levodopa

\begin{abstract}
The management of early Parkinson's disease (PD) involves the treatment of motor symptoms, and, increasingly, nonmotor symptoms. Given the fast pace of clinical research in PD, clinicians are faced with the challenge of integrating the latest findings into the ongoing care of individual PD patients. Part 1 of this 2-part article reviews efficacy and safety data for the newest PD treatment options, as well as for established therapies. Part 2 of the article, presented here, reviews key data relevant to the assessment of potential neuroprotective therapies and the treatment of non-motor symptoms.

Copyright $\odot 2009$ S. Karger AG, Base
\end{abstract}

\section{Introduction}

The treatment options for Parkinson's disease (PD) are rapidly expanding. The American Academy of Neurology published evidence-based practice parameters of selected topics in the management of PD in 2006 [1-3]; however, the review did not include the management of early PD since there were no major changes since the last guidelines. Evidence-based treatment guidelines for early PD were published by the American Academy of Neurology in 2002 [4] and the Movement Disorder Society in 2005 [5], but since then new drugs and formulations have become available for the management of the disease.

$\mathrm{PD}$ is a multifaceted disorder comprised of both motor and non-motor symptoms at all stages of the disease. This review seeks to integrate data from the newest treatment options with data from established therapies, so as to provide an up-to-date evidence-based reference for clinicians treating early $\mathrm{PD}$. The article is presented in 2 parts: a review of the efficacy and safety of treatments for PD motor symptoms (part 1) and a review of key clinical trials examining potential neuroprotective therapies for $\mathrm{PD}$ and non-motor manifestations of PD (part 2). The following text is part 2 .

\section{Beyond Symptomatic Therapy: Neuroprotection Studies in PD}

Neuroprotective therapies are interventions that produce enduring benefits by favorably influencing the underlying etiology or pathogenesis of neurodegenerative

\section{KARGER \\ Fax +41613061234 E-Mail karger@karger.ch} www.karger.com
(C) 2009 S. Karger AG, Basel 0014-3022/09/0614-0206\$26.00/0

Accessible online at: www.karger.com/ene
Tanya Simuni, MD

Northwestern University

710 North Lake Shore Drive, 1126

Chicago, IL 60611 (USA)

Tel. +1 312503 2970, Fax +1 312908 5073, E-Mail tsimuni@nmff.org 
disorders [6]. Although there is currently no definitive methodology to assess neuroprotection in PD patients [7], multiple attempts have been made to assess the effects of medications on disease progression.

\section{L-Dopa}

In the ELLDOPA trial, treatment outcome was assessed after a 2 -week washout period following 40 weeks of treatment with L-dopa or placebo [8]. The change from baseline in UPDRS scores remained significantly lower (better) in each L-dopa group compared to the placebo group even after the washout, a result that is potentially consistent with neuroprotection, though also consistent with a long-duration symptomatic effect from L-dopa. In contrast, disease progression, as assessed by dopamine transporter (DAT) binding at baseline and 40 weeks using $\beta$-CIT single photon emission computed tomography (SPECT), was greater in the L-dopa groups than in the placebo group, a result that is consistent with a more rapid progression of the disease or a pharmacologic or pharmacodynamic effect of L-dopa on the DAT. Additional studies will be needed to reconcile the discrepancies between the clinical and neuroimaging data. At the current time, there is no clear evidence that L-dopa either hastens or slows disease progression.

\section{Dopamine Agonists}

The dopamine agonists (DAs) pramipexole and ropinirole exert neuroprotective effects in cell culture and animal models through antioxidative and anti-apoptotic mechanisms [9], and have been tested in clinical trials using SPECT or PET imaging techniques. The CALM-PD trial [10] compared pramipexole and L-dopa treatment over a period of 4 years, measuring estimated neuronal loss by DAT binding after 22,34 and 46 months using $\beta$ CIT SPECT. Pramipexole treatment significantly reduced the loss of DAT binding at all 3 time points when compared to L-dopa ( $\mathrm{p}=0.004,0.009$ and 0.001 at 22,34 and 36 months, respectively). The REAL-PET [11] study compared ropinirole and L-dopa treatment over 2 years and used ${ }^{18} \mathrm{~F}$-dopa uptake detected by PET to assess neuronal loss. Ropinirole-treated patients had a smaller reduction in ${ }^{18} \mathrm{~F}$-dopa uptake (13.4\%) compared to those treated with L-dopa $(20.3 \%, \mathrm{p}=0.022)$. Although these results are consistent with neuroprotection with a DA or neurotoxicity with L-dopa, other pharmacological effects may underlie the apparent neuronal preservation observed with ropinirole and pramipexole compared to L-dopa. Both DAs and L-dopa can, to varying degrees, alter aromatic acid decarboxylase levels and activity, and therefore the apparent amount of ${ }^{18} \mathrm{~F}$-dopa uptake $[12,13]$. Similarly, as SPECT analysis relies on the amount of DAT expressed, modulation of DAT levels by DAs or L-dopa may influence the estimation of neuronal preservation $[12,14]$. These studies also are handicapped by the absence of placebo data and the lack of correlation between imaging and clinical measures of motor disability, making the interpretation of neuroprotection less than conclusive.

Rotigotine has exhibited neuroprotective properties in mouse and non-human primate models of PD [15-17], but neuroprotection has not been proven clinically. In a study of progressive MPTP (1-methyl-4-phenyl-1,2,3,6tetrahydropyridine) lesioning of macaques, treatment with rotigotine for 38 days followed by a two-week washout reduced motor disability and increased postmortem striatal DAT binding compared to treatment with vehicle [17]; however, in vivo measurement of DAT using SPECT failed to reveal differences between rotigotine and vehicle groups, suggesting that in vivo SPECT assessment is not as sensitive as postmortem DAT labeling. Studies in PD patients are required to determine if rotigotine can provide a neuroprotective effect in the clinical setting.

\section{MAO-B Inhibitors}

The irreversible MAO-B inhibitors selegiline and rasagiline confer mild symptomatic benefits for PD through $\mathrm{MAO}-\mathrm{B}$ inhibition, but also may provide neuroprotection through independent mechanisms such as inhibition of GAPDH nuclear translocation and upregulation of Bcl-2 and other anti-apoptotic messengers [18]. The clinical assessment of neuroprotection by these agents is challenging because of their symptomatic benefits, which can confound the interpretation of clinical trials; nevertheless, several large-scale trials have been undertaken.

In the DATATOP trial, selegiline treatment delayed the requirement for L-dopa, but when treatment was halted, patients taking the MAO-B inhibitor worsened more than those given placebo, such that there were no differences between groups at the end of the washout period [19]. Subsequently, all patients were treated with open-label selegiline, creating a delayed-start trial paradigm [20]. No differences were found in UPDRS scores or other outcomes between patients continuously treated with selegiline and those who were later switched from placebo to selegiline, suggesting that selegiline failed to have any impact on the course of the disease. Another study examined treatment from untreated baseline to untreated endpoint following washout of symptomatic therapy with bromocriptine or L-dopa plus additional treatment with selegiline or placebo. Selegiline was discontinued 2 
months before the final UPDRS assessment in an attempt to ensure complete washout of drug [21]. The authors found a significant difference in favor of selegiline-treated subjects, but it is not possible to determine if all of the symptomatic effects of selegiline were resolved by the washout. Even so, it is interesting to note that, despite a 2-month washout, selegiline still provided as much benefit as L-dopa, suggesting that neuroprotection may have been achieved.

Rasagiline has been investigated in 2 trials. The TEMPO study employed a delayed-start design [22]. At 12 months, patients taking rasagiline from the start of the trial had significantly lower UPDRS scores (less disability) than those who initiated rasagiline after 6 months of placebo treatment, suggesting that the earlier administration of rasagiline may have provided neuroprotection. This study has been extended for 6.5 years, and at several (but not all) time points, the delayed-start subjects showed significantly greater impairment on the UPDRS compared to subjects who initiated the trial with rasagiline [23]. A larger trial of rasagiline that was designed to confirm the results of the TEMPO study has been just completed: the ADAGIO study [24] also used a delayed-start design, but enrolled a larger cohort of subjects $(n=1,176)$, had a longer duration (72 weeks) and investigators remained blinded to the treatment assignment for the duration of the study. In the first phase of the study, subjects with early untreated PD were randomized to rasagiline $1 \mathrm{mg} /$ day, $2 \mathrm{mg} /$ day or matching placebo. After 36 weeks, the group initially treated with placebo was switched to 1 or $2 \mathrm{mg}$ /day active treatment in a double-blind fashion. The study evaluated the change in UPDRS score from baseline to endpoint across each same-dose early and delayed-start group, and results from the complete report are awaited.

\section{Other Treatments}

The Neuroprotection Exploratory Trials in Parkinson's disease (NET-PD) initiative has been implemented by the NIH in order to 'fast track' evaluation of potential neuroprotective agents. Futility trials have been conducted to determine whether further studies of GPI-1485, minocycline, creatine and coenzyme $\mathrm{Q}_{10}\left(\mathrm{CoQ}_{10}\right)$ are warranted [25]. In these studies, progression of clinical disability was compared to progression of the placebo arm in the DATATOP study. Based on this predefined comparison to historical controls, none of these agents were found to be futile [26, 27]; however, an exploratory analysis adjusting the futility threshold using the placebo groups from contemporaneous trials suggested that GPI-
1485 , minocycline and $\mathrm{CoQ}_{10}$ were futile, whereas creatine was not [27]. Therefore, creatine is now being investigated further. A large trial of $\mathrm{CoQ}_{10}$ is planned, based on the positive results from a previous trial that used mid-range doses [28].

Creatine is hypothesized to act as a mitochondrial stabilizer. A second study investigated treatment with creatine over 2 years and found no effect on DAT-SPECT or UPDRS scores, although increases in concomitant DA dosages were significantly reduced in subjects given creatine and mood was improved [29]. A large long-term clinical trial of creatine is now underway [30].

Two neurotrophic factors have been tested in $\mathrm{PD}$ patients: glial-derived neurotrophic factor (GDNF) and neurturin. The effects of GDNF treatment in 2 open-label trials generated much optimism that this molecule might provide neuroprotection as well as restorative benefits $[31,32]$; however, a double-blind trial was halted due to lack of efficacy and the development of antibodies to GDNF in $10 \%$ of patients [33]. In concurrent experiments, it was found that some non-human primates exhibited cerebellar degeneration following GDNF withdrawal [34]. The causes of these problems remain unclear, although the method of delivery (via cannula) has been criticized. Neurturin is a sister molecule to GDNF and has been examined in 1 open-label study. Neurturin was found to be safe and efficacious in advanced PD patients when delivered using an adeno-associated virus, conferring significant reductions in UPDRS scores and 'off' time [35]. Neurturin is currently undergoing further testing in a larger phase I/II trial.

No treatment has been proven to provide neuroprotection in PD. Clinical trials attempting to assess neuroprotection have had potential confounders, such as observed symptomatic effects, possible incomplete washout and possible compensatory pharmacological effects affecting imaging techniques. Further trials are necessary to investigate putative neuroprotective benefits of potential candidate medications.

\section{Time to Initiate Treatment in Early PD}

The timing of initiation of symptomatic therapy has been one of the most debated subjects in the management of early PD, and there still is no consensus. In the past, the preferred strategy was to delay the initiation of symptomatic treatment due to the concern of potential longterm negative effects of dopaminergic therapy on the rate of PD progression, a concern that stems from the hypoth- 
esis of a neurotoxic effect of L-dopa caused by the production of free oxygen radicals that could further potentiate the degenerative process in the substantia nigra [36]. However, several lines of evidence do not support the hypothesis of L-dopa toxicity [37]. While L-dopa has been shown to potentiate cell death in tissue culture, the concentration of $\mathrm{L}$-dopa in those experiments far exceeded the concentrations achieved in humans. Animal data also do not demonstrate a neurotoxic effect of L-dopa at doses that approximate human use [38]. Most importantly, data from the ELLDOPA trial demonstrated clinically that early initiation of L-dopa was not deleterious, but rather resulted in a reduction of disability [8]. However, the imaging component of the trial was potentially consistent with a neurotoxic effect, and an increased risk of dyskinesia was observed. Thus, while L-dopa remains the most efficacious agent for the treatment of PD, the timing of initiation of L-dopa must be balanced against the risk of drug-induced motor complications.

An alternative strategy is the initiation of treatment with DAs or MAO-B inhibitors; however, the benefit of DAs has to be weighed against their relatively high rate of side effects, specifically drug-induced sedation and impulse control disorders. MAO-B inhibitors have few side effects, but are less efficacious than other dopaminergic agents. The current standard of practice is to initiate symptomatic therapy at the time of functional disability $[4,5]$. The limitation of such an approach is that there is substantial variability in the interpretation of what constitutes functional disability. One of the major arguments against early initiation of treatment in PD has been the lack of a proven neuroprotective agent, and therefore a lack of 'urgency' to initiate treatment. While there remains no proven neuroprotective agent in $\mathrm{PD}$, multiple clinical trials including the ELLDOPA (L-dopa) and TEMPO (rasagiline) studies suggest that early initiation of symptomatic therapy reduces the accumulation of disability. These data should serve as the rationale for physicians to offer symptomatic therapy early in PD, while carefully weighing the immediate and long-term benefits against potential side effects.

\section{Treatment of Non-Motor Symptoms}

Until recently, the majority of PD clinical trials were designed to assess the efficacy of novel therapeutic agents for motor disability; however, based on the results of a large survey of PD patients, depression and non-motor disability were found to be the major contributing factors to impairments in disease-related quality of life [39]. The scope of non-motor manifestations of PD is broad, and includes disturbances in mood, cognition, autonomic function, sleep, perceptual changes and impulse control. The pathogenesis of non-motor symptoms in PD is complex and not fully understood, but is believed to be related to the widespread nature of dopaminergic dysfunction involving structures beyond the substantia nigra, as well as the presence of PD-related pathology in non-dopaminergic nuclei, such as the locus coeruleus, nucleus basalis of Meynert and raphe nuclei [40]. In the past, nonmotor symptoms were attributed to more advanced stages of PD; however, it is now known that many can manifest early in the course of the disease and can even precede the onset of motor symptoms (e.g. anosmia, depression, sleep dysfunction). The high prevalence, associated disability and often early occurrence of non-motor symptoms in PD not only warrant the development of therapeutic agents aimed specifically at their treatment, but also necessitate the reevaluation of existing PD agents for potential benefits in alleviating non-motor symptoms.

\section{Depression}

Depression remains the major factor contributing to quality of life impairments in PD. Depression can occur early in the course of the disease, and can even precede the onset of motor disability. Early recognition and treatment of depression is essential for effective disease management. The current estimated prevalence of depression in PD is $40 \%$, though prevalence in early stages of the disease has not been well established [41]. Compared to depressive disorders in non-PD populations, depression in PD is often characterized by less guilt and lower suicide ideation, but higher rates of anxiety, pessimism and irrationality [42]. Similar to elderly patients in general, $\mathrm{PD}$ patients more commonly suffer from less severe forms of depression (i.e. minor depression and dysthymia rather than major depression). Other symptoms frequently seen in the spectrum of PD-related mood dysfunction include anhedonia (i.e. loss of pleasure), apathy (i.e. loss of interest or motivation) and anxiety.

Despite the high prevalence of depression in PD, there is a paucity of well-designed controlled clinical trials that systematically evaluate the efficacy of standard antidepressants or dopaminergic therapy for mood dysfunction, and no studies focusing on mood disorders in early PD have been performed. Recently published practice parameters on the treatment of depression in PD identified only 6 well-controlled studies, some of which were not sufficiently powered to detect efficacy of the tested agent 
[43]. The conclusion of the practice parameter was that there is insufficient evidence to support or refute the efficacy of most antidepressants in the treatment of depression in PD; however, 'lack of literature demonstrating clear efficacy of antidepressants is not the same as absence of efficacy'. A recent meta-analysis reviewed all English language studies published on the efficacy of antidepressants in PD from 1965 to December 2003 [44]. The data analysis concluded that there was a large effect size for both active treatment and placebo groups, but there was no significant difference between the two. Additional data are necessary and a number of studies are ongoing; however, in clinical practice, SSRIs (selective serotonin reuptake inhibitors) are the most commonly used antidepressants for the treatment of depression in PD [45].

Limited data on the role of dopaminergic therapy in the treatment of depression in PD are available [46, 47]. Pramipexole was shown to have comparable efficacy to sertraline for the treatment of depression in PD; however, the open-label trial design and low dose of sertraline used in that study limits the findings [48]. A randomized placebo-controlled study of pramipexole for depression in patients with early PD in Europe was recently completed, but the results have not been presented yet.

\section{Cognitive Dysfunction}

Compared to depression, which can be seen early in the course of PD, dementia is a manifestation of advanced disease; however, signs of cognitive dysfunction can be seen even in the early stages of PD. In a study of 115 consecutive newly diagnosed PD patients compared to 70 healthy controls, $24 \%$ of the newly diagnosed PD patients versus $4 \%$ of the controls had abnormal performance on at least 3 neuropsychological tests, with impairment predominately in the domains of executive function and psychomotor speed [49]. The profile of cognitive impairment in PD is frequently labeled as 'dysexecutive syndrome' and characterized by impaired visuospatial abilities, attention, retrieval memory and executive function, with relative preservation of encoding memory, praxis and language compared with the mild cognitive impairment that precedes Alzheimer's disease [50, 51]. The recommendations for the diagnostic evaluation of dementia in $\mathrm{PD}$ were recently published by the Movement Disorders Society task force [52].

Although no data on the treatment of mild cognitive impairment in early PD are available, a number of studies have investigated the role of cholinesterase inhibitors in the treatment of PD dementia. The largest study $(n=541)$ demonstrated a statistically significant but modest clinical benefit of rivastigmine (oral formulation) over placebo [53]. The most common side effects were gastrointestinal in nature, which is typical for this class of drug, and the worsening of PD tremor by patient report, though UPDRS scores did not reflect this. Based on this study and others, oral rivastigmine and more recently the transdermal patch, which is associated with less nausea and vomiting, have received FDA approval for the treatment of PD dementia. In smaller studies, other cholinesterase inhibitors also have been shown to be effective in the treatment of PD dementia [54]. While no data on the efficacy of the NMDA (N-methyl-D-aspartate) receptor antagonist memantine in the management of PD dementia have been published, studies are under way. Additional studies are necessary to evaluate the efficacy of all of these agents in patients with mild cognitive impairment in early PD.

\section{Sleep Dysfunction}

Disorders of sleep and wakefulness are ubiquitous in PD, with an estimated prevalence of 98\% [55]. Sleep dysfunction can occur early in the course of PD, and PD-associated sleep dysfunction spans the spectrum of sleep pathology. The etiology is multifactorial and includes PD pathology affecting the reticular activating system, which, according to Braak et al. [40], is involved early in the course of the disease process. PD-related motor dysfunction directly impacting sleep quality and side effects of complex PD pharmacological therapy also play a role. Some of the specific problems that commonly contribute to sleep fragmentation and poor sleep efficiency in PD patients include parasomnias: specifically, rapid eye movement sleep behavior disorder (RBD), which is present in about $15-33 \%$ of patients [56], restless legs syndrome and obstructive sleep apnea [57]. RBD is of particular significance in early $\mathrm{PD}$ as it can precede the onset of motor disability by a number of years and is considered to be a potential premotor sign of PD [58]. Excessive day time sleepiness (EDS) occurs in up to $50 \%$ of PD patients [59]. Interestingly, a prospective survey of 3,078 elderly men in the Honolulu-Asia Aging Study demonstrated that preexisting EDS was one of the risk factors for development of PD [60]. Risk factors for EDS in PD include advanced age, presence of cognitive dysfunction and cumulative dose of dopaminergic therapy [61]. Surprisingly, EDS does not correlate with the quality of nocturnal sleep. In addition to the more common sleep problems, a phenomenon of sudden onset sleep (SOS) - described as unintended episodes of sleep that occur without premon- 
itory signs - has been reported in PD patients [62]. SOS was initially attributed to a specific DA, but later was described as occurring with the use of any dopaminergic therapy [63]. While SOS is rare, all patients treated with dopaminergic agents should be counseled, and appropriate measures should be taken if episodes occur. Assessment for EDS and SOS is especially important in patients with PD who drive.

Treatment of sleep dysfunction in PD should focus on an accurate diagnosis of the specific problem. PD medications should be reviewed and simplified if possible, and sleep studies should be ordered if other causes of sleep dysfunction are suspected. RBD can be effectively managed with clonazepam [56], though placebo-controlled studies are lacking, and nocturnal confusion can occur with bedtime benzodiazepine use in the geriatric population. Melatonin was reported to be effective in 1 small study at dose ranges of 3-12 mg and is generally well tolerated [64]. Donepezil, pramipexole and L-dopa have also been reported to be effective, though experience is limited to case reports $[65,66]$. Restless legs syndrome is readily responsive to DAs $[67,68]$. Use of hypnotics should be limited to cases that do not respond to behavioral modifications and other measures, as there are no efficacy data for specific hypnotic agents in PD. Physicians also should be vigilant about the treatment of depression and psychosis, as these are possible contributing factors to sleep dysfunction in PD patients. Treatment of EDS is challenging because the majority of dopaminergic agents can cause EDS; reducing or changing DAs should be attempted [69]. Modafinil has shown mixed results for PD-related EDS [69], with some studies showing mild improvement [70] and others showing no improvement [71].

\section{Psychosis}

Psychosis usually occurs later in the course of PD. Psychosis very early in the disease course suggests a diagnosis of dementia with Lewy bodies [72]. Exposure to dopaminergic therapy has been implicated as the major cause of psychosis in PD [73], and DAs are more prone to cause psychosis than L-dopa even in early PD. In a placebo-controlled study of $3 \mathrm{~L}$-dopa dosages, hallucinations were not reported as an adverse event in any of the treatment groups [8]. Comparing L-dopa to DA treatment, in a randomized comparison study of pramipexole and L-dopa in early PD, hallucinations were more common during the escalation phase in the pramipexole- versus the L-dopatreated group (6.6 vs. 1.3\%, respectively) [74]. Similarly, in a randomized comparison study of ropinirole and Ldopa in early PD, hallucinations were reported more fre- quently in the ropinirole- versus the L-dopa-treated group (17.3 vs. $5.6 \%)$ [75].

If psychotic symptoms in $\mathrm{PD}$ are significant enough to warrant intervention, the first step is to discontinue any non-essential non-PD medications that might contribute to mental impairment. Next, the risk:benefit ratio of each antiparkinsonian medication should be reviewed. In conjunction with the steps outlined above, antipsychotic treatment is initiated for persistent and problematic psychosis. Clozapine has been shown to be efficacious for PD psychosis in placebo-controlled studies at much lower dosages (mean dosages of $25-36 \mathrm{mg} /$ day) than typically used in psychiatric populations [76,77], but it is usually reserved for treatment-refractory patients. Clinically, quetiapine has become the most commonly used antipsychotic, a preference based upon clinical experience, the results of several positive open-label studies [78-81], and less adverse impact on parkinsonism than reported with typical antipsychotics and even other atypical antipsychotics [82].

\section{Impulse Control Disorders}

Over the last couple of years, there have been an increasing number of publications reporting impulse control disorders (ICDs) in PD patients [83]. ICDs are defined as failure to resist an impulse or temptation to perform an act that is harmful to the patient or others. The most common clinical manifestations of ICDs in PD are compulsive gambling, sexual behavior, buying and eating. A recently completed cross-sectional study of 3,090 treated PD patients reported an overall prevalence of ICD of $13.6 \%$ and a prevalence of ICD of $17.1 \%$ in patients treated with a DA [84]. The frequency of each ICD for the entire population was: compulsive buying (5.7\%), problem or pathological gambling (5.0\%), binge-eating disorder (4.3\%) and compulsive sexual behavior (3.5\%); over one third of patients with an ICD had more than one. ICDs were more common in DA-treated patients than in nonDA-treated ones (17.1 vs. $6.9 \%$, respectively; odds ratio $=$ 2.72, 95\% CI: 2.08-3.54, p < 0.001). Among individual DAs, there was no difference in ICD frequency for pramipexole- and ropinirole-treated patients ( 17.7 vs. $15.5 \%$, respectively; odds ratio $=1.22,95 \%$ CI: $0.94-1.57, \mathrm{p}=0.14$ ). Variables independently associated with an ICD on logistic regression analyses were younger age, DA treatment (both any treatment and higher dosage), L-dopa dosage (both any treatment and higher dosage), not being married and a self-reported family history of gambling problems (all $\mathrm{p} \leq 0.01$ ). Thus, from the results of this study and others, the strongest risk factor for ICD development 
appears to be DA treatment, with additional risk factors being a history of related behaviors or substance abuse, younger age and male sex [83-86]. Additional data are necessary, but all patients who are to be treated with a DA should be counseled in advance about the potential risk for the development of 1 or more ICDs. Although there is no controlled treatment research, management options for patients with an ICD include discontinuation of the $\mathrm{DA}$, using a lower DA dosage, switching to a different DA or adding a psychiatric medication (e.g. an SSRI) [87].

\section{Autonomic Dysfunction}

Autonomic dysfunction (ADS) is an intrinsic part of $\mathrm{PD}$ symptomatology. The spectrum of ADS in PD is broad and includes orthostatic hypotension, bladder and bowel dysfunction, erectile dysfunction and hyperhidrosis. Despite prior belief that ADS is a manifestation of advanced PD, ADS symptoms can be present early in the course of the disease and can have a major impact on quality of life [88, 89]. The etiology of ADS in PD is believed to be related to the spread of Lewy body pathology to the autonomic centers, augmented by the potential negative impact of dopaminergic medications on at least some of the symptoms (e.g. orthostatic hypotension and constipation). Studies have reported efficacy of domperidone, a peripheral dopamine receptor blocking agent, and pyridostigmine, a peripheral cholinesterase inhibitor, for the management of orthostatic hypotension in PD $[90,91]$. While there is an increasing amount of data on the prevalence of ADS in $\mathrm{PD}$, there is paucity of literature on disease-specific treatment options. Physicians should use a standard symptomatic treatment approach to manage ADS as in other disorders, but with an awareness of potential $\mathrm{PD}$-specific side effects (e.g. confusion with the use of drugs for neurogenic bladder dysfunction).

\section{Anosmia and Other Sensory Manifestations of PD}

Loss of smell has long been reported to be an early sign of $\mathrm{PD}$, present in $70-100 \%$ of $\mathrm{PD}$ patients [92]. As the loss of smell frequently can precede the onset of motor symptoms, recent research has focused on the role of smell-testing in the early identification of PD [92]. If proven to be sensitive and specific, a smell test would be an easy-to-administer inexpensive screening tool that would be useful for identifying populations at risk of PD and for enrollment in neuroprotection clinical trials. Anosmia does not improve with dopaminergic therapy, and thus cannot be used as a measure of efficacy for dopaminergic agents.

Pain is another common manifestation of PD [93]. The pattern and distribution of pain varies, but a subset of patients experiencing pain is responsive to dopaminergic therapy [93]. The nature of pain in PD is likely multifactorial, and more data on the mechanisms of pain and potential disease-specific treatment interventions are necessary.

\section{Conclusions}

Halting the progression of PD is currently a significant unmet need in the treatment of PD, despite a large number of clinical trials designed to investigate potential neuroprotective agents. The research effort to find effective neuroprotective agents is ongoing and will hopefully ultimately lead to the discovery of effective disease-modifying strategies. Clinicians will have to weigh newly evolving evidence as it becomes available to decide if potential neuroprotective benefits outweigh the cost and potential side effects for individual patients. Non-motor symptoms of PD can manifest even early in the disease and cause significant impact on patient quality of life. Recent data provide a better understanding of the scope of PD non-motor manifestations. Evaluation of new and existing therapeutic agents for these symptoms is an important focus of current research.

\section{Disclosures}

This review article was supported by UCB. T.S. has received consulting fees from UCB, Novartis, GlaxoSmithKline, Boehringer Ingelheim, Vernalis, Valeant and Medtronic. K.E.L. has received honoraria or consulting fees from Teva Neuroscience, Novartis, UCB, Advanced Neuromodulation Systems, GlaxoSmithKline and Valeant. R.P. has received honoraria or consulting fees or has been involved in research studies with UCB, GlaxoSmithKline, Boehringer Ingelheim, Medtronic, Teva Neuroscience, Valeant, Vernalis, Eisai and Solvay Pharma. R.A.H. has received honoraria or consulting fees from Bayer Schering Pharma, Bertek, Boehringer Ingelheim, Centopharm, Eisai, Genzyme, GlaxoSmithKline, Impax, Kyowa Pharmaceutical, Merck, Novartis, Ortho McNeil, Pfizer, Prestwick, Schwarz Pharma, Schering, Solvay Pharma, Teva Neuroscience, Valeant and Vernalis. C.C. has acted as a consultant/advisory board participant for Allergan, Jazz, Cephalon, Merz, Valeant, UCB and Boehringer Ingelheim, and has received research grants (administered through Rush University Medical Center) from Allergan, Ipsen, Solstice, Merz, Boehringer Ingelheim, Solvay, Astra-Zenica and Novartis. L.E. has received honoraria or consulting fees from Boehringer Ingelheim, GlaxoSmithKline, Novartis, Teva Neuroscience, UCB, Valeant and Vernalis, and has received grant support from GlaxoSmithKline. D.W. receives research support from NIMH and Boehringer Ingelheim, and has consulted for Boehringer Ingelheim, Novartis, Osmotica, and EMD Serono. 


\section{References}

1 Suchowersky O, Gronseth G, Perlmutter J, Reich S, Zesiewicz T, Weiner WJ: Practice Parameter: neuroprotective strategies and alternative therapies for Parkinson disease (an evidence-based review). Report of the Quality Standards Subcommittee of the American Academy of Neurology. Neurology 2006;66:976-982.

-2 Suchowersky O, Reich S, Perlmutter J, Zesiewicz T, Gronseth G, Weiner WJ: Practice Parameter: diagnosis and prognosis of new onset Parkinson disease (an evidence-based review). Report of the Quality Standards Subcommittee of the American Academy of Neurology. Neurology 2006;66:968-975.

- 3 Pahwa R, Factor SA, Lyons KE, Ondo WG, Gronseth G, Bronte-Stewart H, Hallett M, Miyasaki J, Stevens J, Weiner WJ: Practice Parameter: treatment of Parkinson disease with motor fluctuations and dyskinesia (an evidence-based review): report of the Quality Standards Subcommittee of the American Academy of Neurology. Neurology 2006; 66:983-995.

4 Miyasaki JM, Martin W, Suchowersky O, Weiner WJ, Lang AE: Practice parameter: initiation of treatment for Parkinson's disease: an evidence-based review: report of the Quality Standards Subcommittee of the American Academy of Neurology. Neurology 2002;58:11-17.

5 Goetz CG, Poewe W, Rascol O, Sampaio C: Evidence-based medical review update: pharmacological and surgical treatments of Parkinson's disease: 2001 to 2004. Mov Disord 2005;20:523-539.

6 6 Shoulson I: Where do we stand on neuroprotection? Where do we go from here? Mov Disord 1998;13(suppl 1):46-48.

7 Hauser RA, Zesiewicz TA: Clinical trials aimed at detecting neuroprotection in Parkinson's disease. Neurology 2006;66(suppl 4):S58-S68

8 The Parkinson Study Group: Levodopa and the progression of Parkinson's disease. $\mathrm{N}$ Engl J Med 2004;351:2498-2508.

$\checkmark 9$ Le WD, Jankovic J: Are dopamine receptor agonists neuroprotective in Parkinson's disease? Drugs Aging 2001;18:389-396.

10 The Parkinson Study Group: Dopamine transporter brain imaging to assess the effects of pramipexole vs. levodopa on Parkinson disease progression. JAMA 2002;287: 1653-1661.

11 Whone AL, Watts RL, Stoessl AJ, Davis M, Reske S, Nahmias C, Lang AE, Rascol O, Ribeiro MJ, Remy P, Poewe WH, Hauser RA, Brooks DJ: Slower progression of Parkinson's disease with ropinirole versus levodopa: The REAL-PET study. Ann Neurol 2003; 54:93-101.
12 Ikawa K, Watanabe A, Kaneno S, Toru M: Modulation of $[3 \mathrm{H}]$ mazindol binding sites in rat striatum by dopaminergic agents. Eur J Pharmacol 1993;250:261-266.

13 Cho S, Neff NH, Hadjiconstantinou M: Regulation of tyrosine hydroxylase and aromatic L-amino acid decarboxylase by dopaminergic drugs. Eur J Pharmacol 1997;323 149-157.

14 Guttman M, Stewart D, Hussey D, Wilson A, Houle S, Kish S: Influence of L-dopa and pramipexole on striatal dopamine transporter in early PD. Neurology 2001;56:15591564.

15 Hill M, Scheller DKA, Bezard E, Crossman A: Subchronic treatment with rotigotine prevents synaptic degeneration in the MPTP mouse model of Parkinson's disease (abstract). Mov Disord 2005;20(suppl 10):S77.

16 Stichel CC, Scheller DKA: Rotigotine prevents neurodegeneration in a mouse model of Parkinson's disease (abstract). Eur J Neurol 2005;12(suppl 2):108.

17 Scheller D, Chan P, Li Q, Wu T, Zhang R, Guan L, Ravenscroft P, Guigoni C, Crossman AR, Hill M, Bezard E: Rotigotine treatment partially protects from MPTP toxicity in a progressive macaque model of Parkinson's disease. Exp Neurol 2007;203:415422.

18 Olanow CW: Rationale for considering that propargylamines might be neuroprotective in Parkinson's disease. Neurology 2006; 66(suppl 4):S69-S79.

19 The Parkinson Study Group: Effects of tocopherol and deprenyl on the progression of disability in early Parkinson's disease. N Engl J Med 1993;328:176-183.

20 Shoulson I, Oakes D, Fahn S, Lang A, Langston JW, LeWitt P, Olanow CW, Penney JB, Tanner C, Kieburtz K, Rudolph A: Impact of sustained deprenyl (selegiline) in levodopatreated Parkinson's disease: a randomized placebo-controlled extension of the deprenyl and tocopherol antioxidative therapy of parkinsonism trial. Ann Neurol 2002;51:604612.

21 Olanow CW, Hauser RA, Gauger L, Malapira T, Koller W, Hubble J, Bushenbark K, Lilienfeld D, Esterlitz J: The effect of deprenyl and levodopa on the progression of Parkinson's disease. Ann Neurol 1995;38:771777.

22 The Parkinson Study Group: A controlled, randomized, delayed-start study of rasagiline in early Parkinson disease. Arch Neurol 2004;61:561-566.

23 Hauser RA, Lew MF, Hurtig HI, Ondo WG Wojcieszek J; TEMPO Extension Study Group: Early treatment with rasagiline is more beneficial than delayed treatment start in the long-term management of Parkinson's disease: a subgroup analysis (abstract). Mov Disord 2005;20(suppl 10):S75.
24 Teva Pharmaceutical Industries: ADAGIO phase III top line data to be presented at 12th Congr Eur Fed Neurol Soc (media release). April 16, 2008.

25 Ravina BM, Fagan SC, Hart RG, Hovinga CA, Murphy DD, Dawson TM, Marler JR: Neuroprotective agents for clinical trials in Parkinson's disease: a systematic assessment. Neurology 2003;60:1234-1240.

26 NINDS NET-PD Investigators: A randomized, double-blind, futility clinical trial of creatine and minocycline in early Parkinson disease. Neurology 2006;66:664-671.

$>27$ NINDS NET-PD Investigators: A randomized clinical trial of coenzyme Q10 and GPI1485 in early Parkinson disease. Neurology 2007;68:20-28.

28 Shults CW, Oakes D, Kieburtz K, Beal MF, Haas R, Plumb S, Juncos JL, Nutt J, Shoulson I, Carter J, Kompoliti K, Perlmutter JS, Reich S, Stern M, Watts RL, Kurlan R, Molho E, Harrison M, Lew M: Effects of coenzyme Q10 in early Parkinson disease: evidence of slowing of the functional decline. Arch Neurol 2002;59:1541-1550.

29 Bender A, Koch W, Elstner M, Schombacher Y, Bender J, Moeschl M, Gekeler F, MullerMyhsok B, Gasser T, Tatsch K, Klopstock T: Creatine supplementation in Parkinson disease: a placebo-controlled randomized pilot trial. Neurology 2006;67:1262-1264.

30 National Institute of Neurological Disorders and Stroke (NINDS): NET-PD LS-1 Creatine in Parkinson's Disease (ClinicalTrials.gov identifier: NCT00449865). http://clinicaltrials.gov/ct2/show/NCT00449865?term $=$ crea tine+AND+Parkinson $\% 27 \mathrm{~s}+$ disease $\&$ rank= 1 (accessed December 11, 2007).

-31 Gill SS, Patel NK, Hotton GR, O'Sullivan K, McCarter R, Bunnage M, Brooks DJ, Svendsen CN, Heywood P: Direct brain infusion of glial cell line-derived neurotrophic factor in Parkinson disease. Nat Med 2003;9:589595.

32 Slevin JT, Gash DM, Smith CD, Gerhardt GA, Kryscio R, Chebrolu H, Walton A, Wagner R, Young AB: Unilateral intraputaminal glial cell line-derived neurotrophic factor in patients with Parkinson disease: response to 1 year each of treatment and withdrawal. Neurosurg Focus 2006;20:E1.

33 Lang AE, Gill S, Patel NK, Lozano A, Nutt JG, Penn R, Brooks DJ, Hotton G, Moro E, Heywood P, Brodsky MA, Burchiel K, Kelly P, Dalvi A, Scott B, Stacy M, Turner D, Wooten VG, Elias WJ, Laws ER, Dhawan V, Stoessl AJ, Matcham J, Coffey RJ, Traub M: Randomized controlled trial of intraputamenal glial cell line-derived neurotrophic factor infusion in Parkinson disease. Ann Neurol 2006;59:459-466. 
-34 Sherer TB, Fiske BK, Svendsen CN, Lang AE, Langston JW: Crossroads in GDNF therapy for Parkinson's disease. Mov Disord 2006;21: 136-141.

35 Marks W, Verhagen L, Metman P, Starr P, Larson P, Bakay R, Taylor R, Lee D, CahnWeiner D, Bartus RT, Ostrem J: Trophic factor gene transfer in Parkinson's disease: preliminary outcomes from the phase I CERE-120 study (abstract). Ann Neurol 2006;60(suppl 10):S71.

-36 Fahn S, Cohen G: The oxidant stress hypothesis in Parkinson's disease: evidence supporting it. Ann Neurol 1992;32:804-812.

- 37 Simuni T, Stern MB: Does levodopa accelerate Parkinson's disease? Drugs Aging 1999; 14:399-408.

- 38 Murer MG, Dziewczapolski G, Menalled LB, Garcia MC, Agid Y, Gershanik O, RaismanVozari R: Chronic levodopa is not toxic for remaining dopamine neurons, but instead promotes their recovery, in rats with moderate nigrostriatal lesions. Ann Neurol 1998; 43:561-575.

-39 Global Parkinson's Disease Survey Steering Committee: Factors impacting on quality of life in Parkinson's disease: results from an international survey. Mov Disord 2002;17: 60-67.

40 Braak H, Ghebremedhin E, Rub U, Bratzke $\mathrm{H}$, Del Tredici K: Stages in the development of Parkinson's disease-related pathology. Cell Tissue Res 2004;318:121-134.

41 Okun MS, Watts RL: Depression associated with Parkinson's disease: clinical features and treatment. Neurology 2002;58(suppl 1): S63-S70.

42 Cummings JL: Depression and Parkinson's disease: a review. Am J Psychiatry 1992;149: 443-454.

43 Miyasaki JM, Shannon K, Voon V, Ravina B, Kleiner-Fisman G, Anderson K, Shulman LM, Gronseth G, Weiner WJ: Practice Parameter: evaluation and treatment of depression, psychosis, and dementia in Parkinson disease (an evidence-based review): report of the Quality Standards Subcommittee of the American Academy of Neurology. Neurology 2006;66:996-1002.

-44 Weintraub D, Morales KH, Moberg PJ, Bilker WB, Balderston C, Duda JE, Katz IR, Stern MB: Antidepressant studies in Parkinson's disease: a review and meta-analysis. Mov Disord 2005;20:1161-1169.

45 Richard IH, Kurlan R: A survey of antidepressant drug use in Parkinson's disease. Parkinson Study Group. Neurology 1997;49: 1168-1170.

46 Lemke MR, Brecht HM, Koester J, Reichmann $\mathrm{H}$ : Effects of the dopamine agonist pramipexole on depression, anhedonia and motor functioning in Parkinson's disease. J Neurol Sci 2006;248:266-270.

-47 Lemke MR: Antidepressant effects of dopamine agonists: Experimental and clinical findings (in German). Nervenarzt 2007;78: $31-38$.
48 Barone P, Scarzella L, Marconi R, Antonini A, Morgante L, Bracco F, Zappia M, Musch B: Pramipexole versus sertraline in the treatment of depression in Parkinson's disease: a national multicenter parallel-group randomized study. J Neurol 2006;253:601-607.

49 Muslimovic D, Post B, Speelman JD, Schmand B: Cognitive profile of patients with newly diagnosed Parkinson disease. Neurology 2005;65:1239-1245.

50 Emre M: Dementia associated with Parkinson's disease. Lancet Neurol 2003;2:229237.

51 Emre M, Aarsland D, Brown R, Burn DJ, Duyckaerts C, Mizuno Y, Broe GA, Cummings J, Dickson DW, Gauthier S, Goldman J, Goetz C, Korczyn A, Lees A, Levy R, Litvan I, McKeith I, Olanow W, Poewe W, Quinn N, Sampaio C, Tolosa E, Dubois B: Clinical diagnostic criteria for dementia associated with Parkinson's disease. Mov Disord 2007; 22:1689-1707, quiz 1837.

52 Dubois B, Burn D, Goetz C, Aarsland D, Brown RG, Broe GA, Dickson D, Duyckaerts C, Cummings J, Gauthier S, Korczyn A, Lees A, Levy R, Litvan I, Mizuno Y, McKeith IG, Olanow CW, Poewe W, Sampaio C, Tolosa E, Emre M: Diagnostic procedures for Parkinson's disease dementia: recommendations from the Movement Disorder Society Task Force. Mov Disord 2007;22:2314-2324

53 Emre M, Aarsland D, Albanese A, Byrne EJ, Deuschl G, De Deyn PP, Durif F, Kulisevsky J, van Laar T, Lees A, Poewe W, Robillard A, Rosa MM, Wolters E, Quarg P, Tekin S, Lane $\mathrm{R}$ : Rivastigmine for dementia associated with Parkinson's disease. N Engl J Med 2004; 351:2509-2518.

54 Leroi I, Collins D, Marsh L: Non-dopaminergic treatment of cognitive impairment and dementia in Parkinson's disease: a review. J Neurol Sci 2006;248:104-114.

55 Simuni T: Somnolence and other sleep disorders in Parkinson's disease: the challenge for the practicing neurologist. Neurol Clin 2004; 22(suppl):S107-S126.

56 Gagnon JF, Postuma RB, Mazza S, Doyon J, Montplaisir J: Rapid-eye-movement sleep behaviour disorder and neurodegenerative diseases. Lancet Neurol 2006;5:424-432.

57 Kumar S, Bhatia M, Behari M: Sleep disorders in Parkinson's disease. Mov Disord 2002;17:775-781.

58 Schenck CH, Bundlie SR, Mahowald MW: Delayed emergence of a parkinsonian disorder in $38 \%$ of 29 older men initially diagnosed with idiopathic rapid eye movement sleep behaviour disorder. Neurology 1996; 46:388-393

59 Hobson DE, Lang AE, Martin WR, Razmy A, Rivest J, Fleming J: Excessive daytime sleepiness and sudden-onset sleep in Parkinson disease: a survey by the Canadian Movement Disorders Group. JAMA 2002;287: 455-463.
60 Abbott RD, Ross GW, White LR, Tanner CM, Masaki KH, Nelson JS, Curb JD, Petrovitch $\mathrm{H}$ : Excessive daytime sleepiness and subsequent development of Parkinson disease. Neurology 2005;65:1442-1446.

61 Gjerstad MD, Aarsland D, Larsen JP: Development of daytime somnolence over time in Parkinson's disease. Neurology 2002;58: 1544-1546.

62 Frucht S, Rogers JD, Greene PE, Gordon MF, Fahn S: Falling asleep at the wheel: motor vehicle mishaps in persons taking pramipexole and ropinirole. Neurology 1999;52:19081910.

63 Homann CN, Wenzel K, Suppan K, Ivanic G, Kriechbaum N, Crevenna R, Ott E: Sleep attacks in patients taking dopamine agonists: review. BMJ 2002;324:1483-1487.

64 Boeve BF, Silber MH, Ferman TJ: Melatonin for treatment of REM sleep behavior disorder in neurologic disorders: results in $14 \mathrm{pa}-$ tients. Sleep Med 2003;4:281-284.

65 Ringman JM, Simmons JH: Treatment of REM sleep behavior disorder with donepezil: a report of three cases. Neurology 2000; 55:870-871

66 Fantini ML, Gagnon JF, Filipini D, Montplaisir J: The effects of pramipexole in REM sleep behavior disorder. Neurology 2003;61: 1418-1420

67 Littner MR, Kushida C, Anderson WM, Bailey D, Berry RB, Hirshkowitz M, Kapen S, Kramer M, Lee-Chiong T, Li KK, Loube DL, Morgenthaler T, Wise M: Practice parameters for the dopaminergic treatment of restless legs syndrome and periodic limb movement disorder. Sleep 2004;27:557-559.

68 Splinter MY: Rotigotine: transdermal dopamine agonist treatment of Parkinson's disease and restless legs syndrome. Ann Pharmacother 2007;41:285-295.

-69 Arnulf I: Excessive daytime sleepiness in parkinsonism. Sleep Med Rev 2005;9:185200

-70 Adler CH, Caviness JN, Hentz JG, Lind M, Tiede J: Randomized trial of modafinil for treating subjective daytime sleepiness in patients with Parkinson's disease. Mov Disord 2003;18:287-293.

-71 Ondo WG, Fayle R, Atassi F, Jankovic J: Modafinil for daytime somnolence in Parkinson's disease: double blind, placebo controlled parallel trial. J Neurol Neurosurg Psychiatry 2005;76:1636-1639.

72 Henderson MJ, Mellers JDC: Psychosis in Parkinson's disease: 'between a rock and a hard place'. Int Rev Psychiatr 2000;12:319334.

73 Wolters EC: Intrinsic and extrinsic psychosis in Parkinson's disease. J Neurol 2001;248 (suppl 3):III22-III27.

74 The Parkinson Study Group: Pramipexole versus levodopa as initial treatment for Parkinson disease: a randomized controlled trial. Parkinson Study Group. JAMA 2000;284: 1931-1938. 
75 Rascol O, Brooks DJ, Korczyn AD, De Deyn PP, Clarke CE, Lang AE: A five-year study of the incidence of dyskinesia in patients with early Parkinson's disease who were treated with ropinirole or levodopa. 056 Study Group. N Engl J Med 2000;342:1484-1491.

-76 The Parkinson Study Group: Low-dose clozapine for the treatment of drug-induced psychosis in Parkinson's disease. The Parkinson Study Group. N Engl J Med 1999;340: 757-763.

-77 The French Clozapine Parkinson Study Group: Clozapine in drug-induced psychosis in Parkinson's disease. The French Clozapine Parkinson Study Group. Lancet 1999; 353:2041-2042.

-78 Fernandez HH, Lannon MC, Friedman JH, Abbott BP: Clozapine replacement by quetiapine for the treatment of drug-induced psychosis in Parkinson's disease. Mov Disord 2000;15:579-581.

-79 Fernandez HH, Friedman JH, Jacques C, Rosenfeld M: Quetiapine for the treatment of drug-induced psychosis in Parkinson's disease. Mov Disord 1999;14:484-487.

-80 Targum SD, Abbott JL: Efficacy of quetiapine in Parkinson's patients with psychosis. J Clin Psychopharmacol 2000;20:54-60.

-81 Dewey RB Jr, O’Suilleabhain PE: Treatment of drug-induced psychosis with quetiapine and clozapine in Parkinson's disease. Neurology 2000;55:1753-1754.
82 Friedman JH, Factor SA: Atypical antipsychotics in the treatment of drug-induced psychosis in Parkinson's disease. Mov Disord 2000;15:201-211.

83 Voon V, Hassan K, Zurowski M, de Souza M, Thomsen T, Fox S, Lang AE, Miyasaki J: Prevalence of repetitive and reward-seeking behaviors in Parkinson disease. Neurology 2006;67:1254-1257.

84 Weintraub D, Koester J, Potenza MN, Siderowf $A D$, Stacy MA, Whetteckey J, Wunderlich GR, Lang AE; DOMINION Study Group: Dopaminergic therapy and impulse control disorders in Parkinson's disease: top line results of a cross-sectional study of over 3,000 patients. Poster Mov Dis Soc 12th Int Congr Parkinson Dis Mov Dis, Chicago, 25 June 2008.

85 Pontone G, Williams JR, Bassett SS, Marsh L: Clinical features associated with impulse control disorders in Parkinson disease. Neurology 2006;67:1258-1261.

86 Weintraub D, Siderowf AD, Potenza MN, Goveas J, Morales KH, Duda JE, Moberg PJ, Stern MB: Association of dopamine agonist use with impulse control disorders in Parkinson disease. Arch Neurol 2006;63:969973.
$>87$ Mamikonyan E, Siderowf AD, Duda JE, Potenza MN, Horn S, Stern MB, Weintraub D: Long-term follow-up of impulse control disorders in Parkinson's disease. Mov Disord 2008;23:75-80.

88 Goldstein DS: Orthostatic hypotension as an early finding in Parkinson's disease. Clin Auton Res 2006;16:46-54.

$>89$ Korchounov A, Kessler KR, Yakhno NN, Damulin IV, Schipper HI: Determinants of autonomic dysfunction in idiopathic Parkinson's disease. J Neurol 2005;252:15301536.

90 Schoffer KL, Henderson RD, O’Maley K, O'Sullivan JD: Nonpharmacological treatment, fludrocortisone, and domperidone for orthostatic hypotension in Parkinson's disease. Mov Disord 2007;22:1543-1549.

-91 Singer W, Opfer-Gehrking TL, McPhee BR, Hilz MJ, Bharucha AE, Low PA: Acetylcholinesterase inhibition: a novel approach in the treatment of neurogenic orthostatic hypotension. J Neurol Neurosurg Psychiatry 2003;74:1294-1298.

92 Katzenschlager R, Lees AJ: Olfaction and Parkinson's syndromes: its role in differential diagnosis. Curr Opin Neurol 2004;17: 417-423.

93 Drake DF, Harkins S, Qutubuddin A: Pain in Parkinson's disease: pathology to treatment, medication to deep brain stimulation. NeuroRehabilitation 2005;20:335-341. 